\title{
OS SENTIDOS DA GESTUALIDADE: TRANSPOSIÇÂO E REPRESENTAÇÃO GESTUAL
}

\author{
SENSES OF GESTURAL LANGUAGE: \\ GESTURAL TRANSPOSITION AND REPRESENTATION
}

\author{
Diana Luz Pessoa de BARROS \\ MACKENZIE - Universidade Presbiteriana Mackenzie \\ USP - Universidade de São Paulo
}

PARA IGNACIO,

MESTRE E AMIGO

\begin{abstract}
RESUMO: Neste artigo são apresentadas, na perspectiva da semiótica discursiva francesa, algumas direções teóricas para o estudo dos sentidos da gestualidade na sociedade contemporânea, em quatro circunstâncias: a gestualidade poética da dança; a gestualidade nos tratamentos de fisioterapia; a passagem do gesto ao "signo" na língua de sinais; a gestualidade representada na pintura, na fotografia, na publicidade, etc. O ponto de partida deste estudo é o texto de Greimas Conditions d'une sémiotique du monde naturel (1970, p.62). Nesse quadro teórico, tratamos de duas questões: das operações de transposição gestual - semantização, dessemantização, mimetização, simbolização, passagem do gesto ao signo, nas línguas de sinais; da representação da gestualidade, em particular na publicidade de bancos, e dos efeitos de sentidos por ela produzidos nesses discursos publicitários.
\end{abstract}

PALAVRAS-CHAVE: Gestualidade; Semiótica; Transposição Gestual; Comunicação Gestual; Gestualidade Representada.

\begin{abstract}
The aim of this article is to present, from the French Discursive-Semiotics approach, some theoretical directions to the study of the senses of gesture in the contemporary society in four circumstances: the poetical gesture of the dance; the gesture in physiotherapy treatment; the passage from the gesture to the "sign' in the sign language; gesture represented in painting, photography, publicity, etc. The main focus of this study begins with the Greimas's study Conditions d'une sémiotique du monde naturel (1970, p.62). From this theoretical outline, we deal with two questions: the operations in gestural transposition - semantization, desemantization, imitation, symbolization, passage from gesture to sign, in sign languages; the representation in gesture language, particularly in bank advertising, and the effects of senses produced in such advertising speeches.
\end{abstract}

KEYWORDS: Gestural Language; Semiotics; Gestural Transposition; Gestural Communication; Gestural Representation. 
Neste artigo, apresentamos, na perspectiva da semiótica discursiva francesa, algumas direções teóricas para o estudo dos sentidos da gestualidade na sociedade contemporânea.

Greimas propõe, no seu texto Conditions d'une sémiotique du monde naturel $(1970,62)$, que a gestualidade seja concebida como uma dimensão semiótica da cultura, pois ela institui diferenças entre culturas, sexos e grupos sociais e dá a eles significação.

O ponto de partida das reflexões que aqui fazemos é, portanto, esse artigo de Greimas e, principalmente, quatro de suas proposições:

- a de incluir as figuras gestuais na subclasse das figuras visuais do mundo natural;

- a de distinguir a práxis gestual da comunicação gestual, pela concepção de "sentido": de direção, quando se trata de práxis gestual, e de remissão, de um código a outro, ou seja, da expressão e do conteúdo, na comunicação gestual;

- a de considerar que o programa da práxis gestual é dessemantizado e seu sentido só é definido pelo projeto gestual, pela direção gestual considerada como significado;

- a de mostrar que há, na comunicação gestual, gestualidades ditas de transposição, como a gestualidade mimética e a gestualidade lúdica, introduzindo a questão das transposições gestuais.

Falaremos da comunicação gestual na segunda parte deste artigo, cujo tema é a gestualidade representada, já que se trata, no caso, da representação da comunicação gestual entre o destinador e o destinatário do texto.

A práxis gestual é transmitida por aprendizagem e se torna uma gesticulação automática por meio de uma operação de dessemantização. A dessemantização pode ser explicada pelo esquema tensivo descendente: há um aumento da extensão do programa gestual levado ao fim, a suas últimas consequências, e um enfraquecimento da tensão afetiva da "carga" semântica de cada movimento gestual que compõe o programa gestual prático. Segundo Greimas (1970), a gestualidade prática não é para o homem senão um bloco significante demarcado, delimitado (p. 66); isto é, passa-se da "visada" à "apreensão" de um todo, de um bloco.

Nesse quadro teórico, tratamos de duas questões: das questões teóricas das operações de transposição gestual - semantização, dessemantização, mimetização, simbolização, passagem do gesto ao signo, nas línguas de sinais; da representação da gestualidade, em particular na publicidade de bancos e dos efeitos de sentido por ela produzidos nesses discursos publicitários.

\section{Algumas direções semióticas para o estudo das transposições gestuais}

Antes de apresentar as direções teóricas para o estudo das transposições gestuais, parece-nos necessário dizer algumas palavras sobre a práxis e a comunicação gestuais. 
Distinguem-se, com Greimas (1970), práxis gestual e comunicação gestual, a partir sobretudo da significação da palavra sentido: remissão de um código a outro ou semiose, na comunicação gestual; direção ou intencionalidade "entre o trajeto a percorrer e seu ponto de chegada", na práxis gestual.

Para propor alguns caminhos semióticos para o estudo das transposições gestuais, partimos das hipóteses que seguem:

- a gestualidade poética da dança-espetáculo ${ }^{1}$ decorre de duas operações semânticas: a ressemantização das figuras gestuais que, antes dessa operação, tinham apenas a significação geral de um programa gestual, ressemantização que opera a passagem da práxis à comunicação gestual; o estabelecimento de relações simbólicas ou semissimbólicas entre a expressão e o conteúdo da comunicação gestual que produzem os efeitos de sentido poético;

- os tratamentos de fisioterapia, também eles, procuram ressemantizar a práxis gestual automática, para que o paciente que perdeu até mesmo o sentido geral do programa gestual (o de direção) possa recuperar esse projeto e, finalmente, torná-lo de novo automático; são, então, duas transposições de sentido, a (re)semantização de programa gestual e, em seguida, sua automatização (nova dessemantização);

- a passagem do gesto ao "signo", na língua de sinais, isto é, a passagem de uma semiótica do mundo natural a uma semiótica das línguas naturais, é a que Greimas (1970) propõe para as línguas naturais em geral: as categorias visuais gestuais, constitutivas da forma da expressão do mundo natural, tornam-se categorias da forma do conteúdo (na sua dimensão figurativa) da língua natural (no caso, a língua de sinais); já que se trata de uma língua natural visual (gestual), é preciso propor ainda transposições de iconização do plano da expressão.

Há, portanto, ao menos quatro operações diferentes a que, genericamente, demos o nome de transposição: a (re)semantização e a dessemantização; o estabelecimento de relações simbólicas ou semissimbólicas entre a expressão e o conteúdo; a passagem das categorias gestuais naturais da forma da expressão dos gestos às categorias figurativas da forma de conteúdo da língua de sinais; a iconização do plano da expressão da língua de sinais.

As operações de (re)semantização e de dessemantização gestuais que caracterizam tanto a dança quanto os tratamentos de fisioterapia podem ser explicadas pelos movimentos tensivos: descendente para a dessemantização, como já vimos a propósito da práxis gestual, em que há aumento da extensão do programa gestual projetado e enfraquecimento da tensão afetiva devido à diminuição da carga semântica dos movimentos gestuais que compõem o programa gestual; ascendente para a (re)semantização, em que há um aumento da tensão afetiva por causa de uma espécie de tomada de consciência "semântica" de cada gesto que forma o programa gestual "carregado de sentido", e uma

\footnotetext{
${ }^{1}$ Mariana de Rosa Trotta examinou a dança nessa perspectiva na sua dissertação de mestrado "O discurso da dança: uma perspectiva semiótica" (USP, 2004) e na sua tese de doutorado (UFF, 2010).
} 
diminuição da extensão do programa que não é mais considerado como um bloco significante delimitado.

A dança e os tratamentos de fisioterapia organizam essas operações de modo

diferente.

A gestualidade da dança caracteriza-se pela ressemantização e pelo estabelecimento de relações simbólicas e semissimbólicas entre a expressão e o conteúdo, de que falaremos mais adiante. Essas duas operações são, do ponto de vista da tensividade, intensificações do sensível, isto é, elas realizam, ambas, o mesmo movimento ascendente que é, dessa forma, exacerbado. A sensorialidade desse tipo de texto é, portanto, reforçada, acentuada.

Já os tratamentos de fisioterapia, que também empregam operações de (re) semantização e de dessemantização, tomam um outro caminho: uma (re)semantização seguida de uma dessemantização. É preciso, primeiramente, dar sentido a cada gesto de um programa gestual prático (por exemplo, para o programa de "sentar-se", é necessário semantizar o gesto de "virar-se", de "dobrar as pernas", de "apoiar as mãos no braço da poltrona" etc), em seguida, é necessário que esses gestos se convertam no bloco gestual automatizado (o programa de "sentar-se", cuja gestualidade "intermediária" é dessemantizada) que eles eram anteriormente, antes da "doença" física e semântica. Em outras palavras, uma intensificação do sensível é seguida de sua atenuação inteligível.

Nos dois casos, no da dança e no dos tratamentos, a gestualidade contribui para a criação do gesto social: graças aos tratamentos da fisioterapia, o homem recupera a gesticulação automática dessemantizada de suas ações individuais e solitárias no mundo; graças à exacerbação do sensível na dança, os homens se comunicam, unem-se, fundem-se corporal, sensorial e intensamente.

Por sua vez, o estabelecimento das relações simbólicas ou semissimbólicas entre a expressão e o conteúdo exacerba, como vimos, a intensidade e o caráter sensível da dança, tornando-a poética. Por essa operação de (semi)simbolização, o aumento da intensidade produzido pela ressemantização da gestualidade prática é acompanhado do mesmo crescimento de intensidade do plano da expressão. As relações entre a expressão e o conteúdo, ambos intensos, criam o semissimbolismo.

Os dois outros tipos de transposição gestual caracterizam a língua de sinais: a passagem das categorias visuais gestuais, constitutivas da forma da expressão do mundo natural, a categorias da forma do conteúdo da língua de sinais; a iconização do plano da expressão. A primeira transposição é a que Greimas preconiza para a constituição da dimensão figurativa do plano do conteúdo de qualquer língua natural. A segunda operação está ligada ao caráter visual da língua de sinais. A iconização cria, então, relações de semelhança entre o plano da expressão da gestualidade visual do mundo natural e o plano da expressão gestual da língua de sinais. Essas relações fabricam "onomatopeias" visuais ou signos icônicos, que são, como qualquer onomatopeia, culturais, mas produzem efeitos de sentido de motivação natural, justamente em razão desse efeito de semelhança entre os signos gestuais do mundo natural e os signos (seu plano da expressão) da língua natural dita "de sinais". As relações entre o mundo natural e a língua de sinais, e as operações de conversão e iconização que ligam esses dois sistemas semióticos indicam, claramente, o lugar da língua de sinais entre as línguas naturais e é o caminho para o exame de suas particularidades linguísticas e semióticas.

Acreditamos que o estudo da gestualidade não pode ser feito sem que sejam consideradas essas transposições gestuais. 
CASA, Vol.8 n.2, dezembro de 2010

\section{A representação da gestualidade}

A gestualidade representada na pintura, na fotografia ou na publicidade assume papéis narrativos e, também, funções retóricas. Se Greimas distingue, como vimos, a práxis gestual da comunicação gestual pela concepção da palavra sentido, é preciso agora examinar as representações dessas diferentes gestualidades nos textos visuais. A gestualidade representada tem funções diferentes segundo os tipos de gestualidade, práxis ou comunicação gestual, e segundo o nível de análise semiótica considerado, nível do enunciado ou da enunciação.

No enunciado, a gestualidade, seja ela práxis ou comunicação gestual, deve ser examinada como procedimento narrativo. Nesse sentido, a gestualidade de pôr os sapatos, de apagar a luz ou de dar nó na gravata investe figurativamente transformações narrativas, modais ou pragmáticas ou estados de sujeitos. Da mesma forma, a gestualidade comunicativa de sacudir a cabeça para concordar com alguém ou a de cumprimentar com um movimento da mão, da cabeça ou dos olhos são coberturas figurativas das relações de comunicação/manipulação entre sujeitos e das interações sensoriais e passionais entre eles. Vejamos um exemplo de anúncio de práxis e um de comunicação gestual representadas no nível do enunciado:

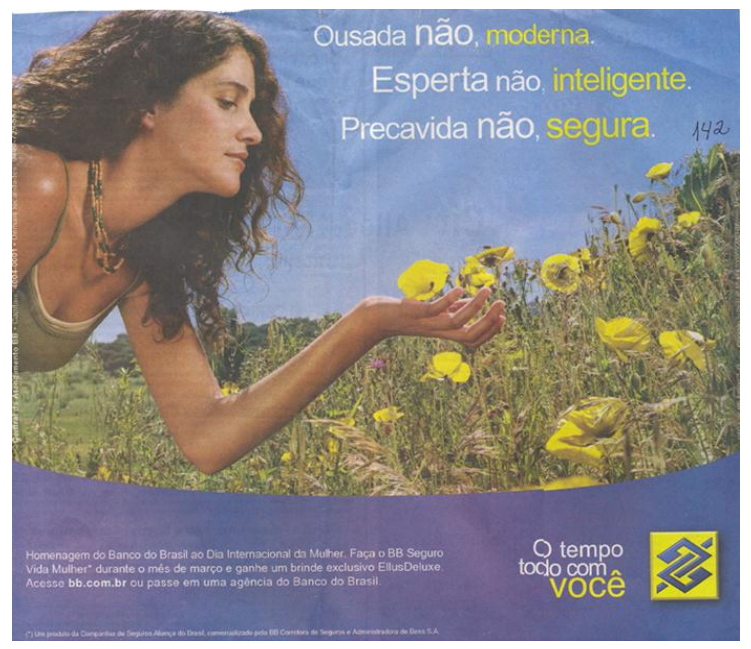




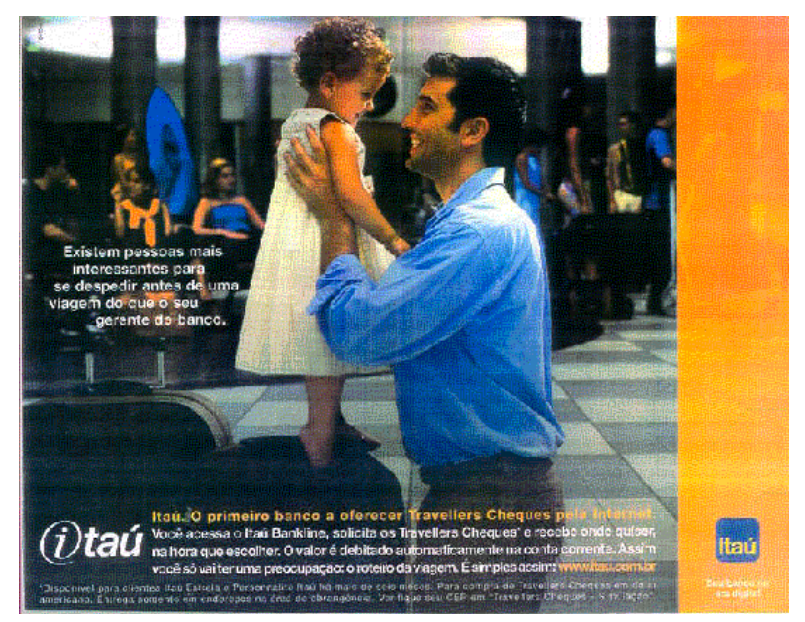

Não vamos tratar aqui da gestualidade narrativa do enunciado, mais conhecida e estudada. Vamos ocupar-nos apenas da gestualidade representada no nível da enunciação. Nesse nível, trata-se da comunicação gestual entre o enunciador e o enunciatário ou entre o narrador e o narratário. A representação da comunicação gestual entre enunciador/narrador e enunciatário/narratário será examinada em anúncios publicitários de bancos. A partir das proposições de Greimas, que distingue dois tipos de gestualidade do ponto de vista da comunicação - a gestualidade de comunicação direta e a gestualidade de transposição -, pudemos determinar (BARROS, 1974) os papéis desses diferentes tipos de gesticulação.

A comunicação gestual, em geral, tal como proposta por Greimas, cumpre cinco das funções jakbsonianas da linguagem: a função fática, a função apelativa e a função emotiva, na gestualidade de comunicação direta; a função metalinguística (gestualidade mimética) e a função estética (gestualidade lúdica), na gestualidade de transposição. A gestualidade mimética, como foi dito, é uma gestualidade de transposição, que tem função metalinguística. Ela fala dos signos visuais ou gestuais da práxis gestual. Os melhores exemplos no corpus examinados são anúncios do Banco Itaú, que criaram uma espécie de logotipo gestual do Banco: um dedo para fazer gestualmente o arroba, mas com $i$, a letra inicial do nome do Banco, para acentuar sua modernidade tecnológica. O gesto é dirigido diretamente ao destinatário-cliente:

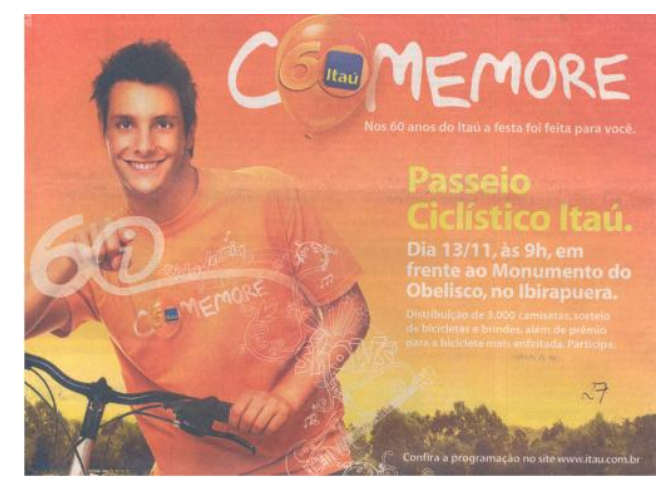


CASA, Vol.8 n.2, dezembro de 2010

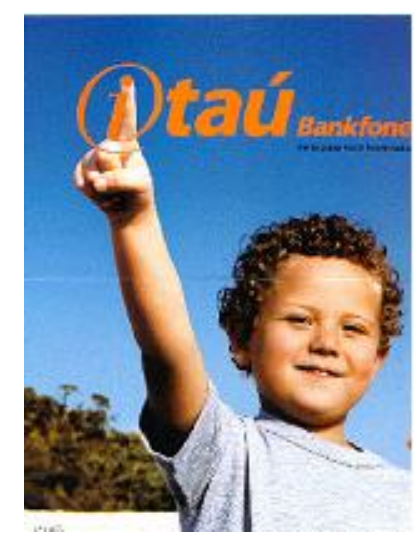

Se a comunicação gestual pode ter várias funções, ela é, em geral, pobre no que diz respeito à função informativa ou referencial da linguagem. Segundo Greimas (1970, p. 40), quem gesticula só pode falar de si mesmo e se revela incapaz de contar o mundo. Os gestos mais próximos dessa função que encontramos no material analisado são os gestos de "mostrar" ou de "indicar" que, embora tenham função predominantemente conativa ou apelativa, assumem também o papel de dar informação sobre o que é mostrado. São, em geral, movimentos da mão, dos dedos (apontar com o dedo), da cabeça ou expressões do rosto. Vejamos alguns exemplos do gesto de mostrar:

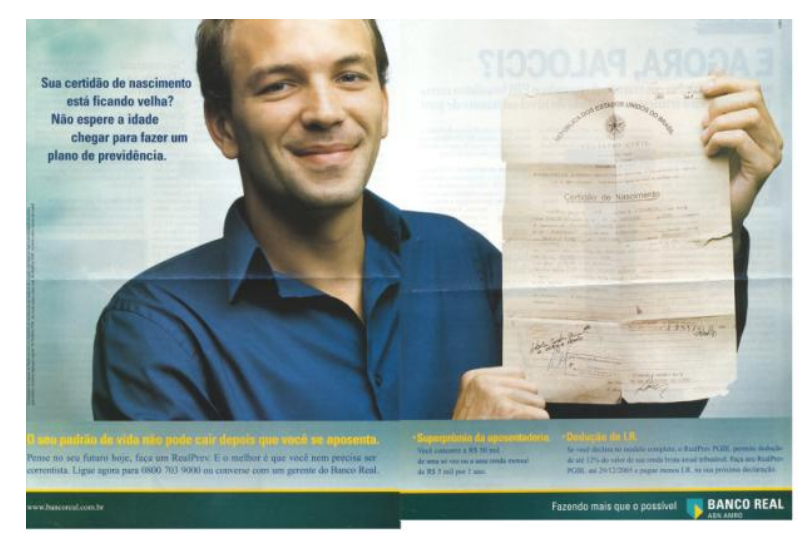


CASA, Vol.8 n.2, dezembro de 2010
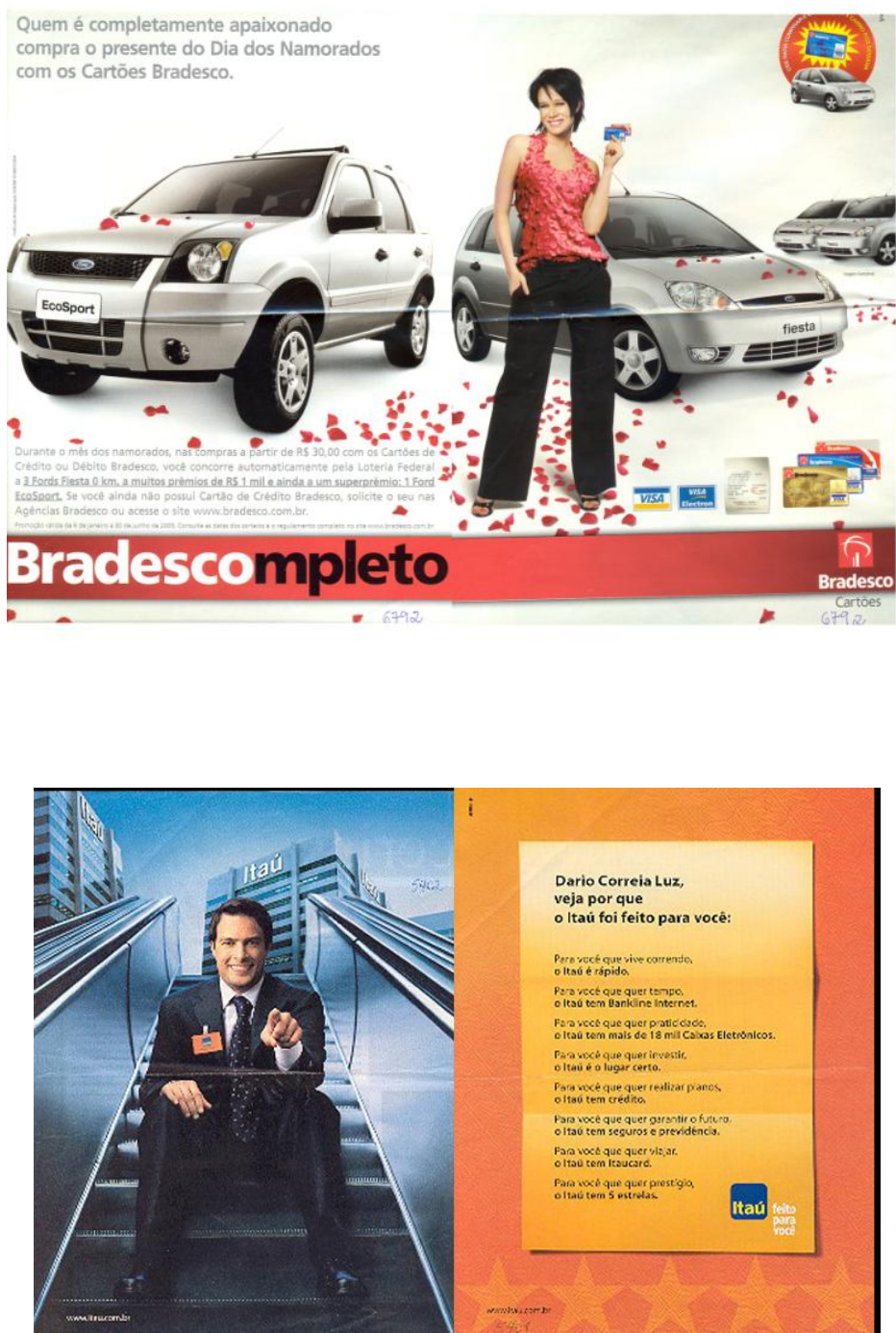


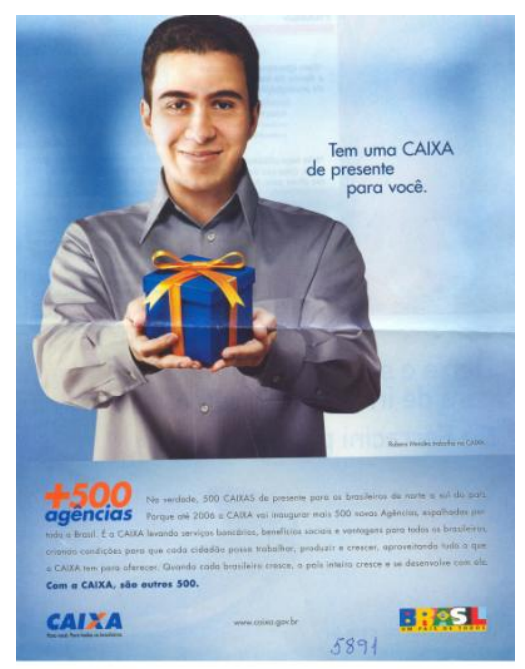

A comunicação gestual com função fática e/ou apelativa e/ou emotiva é a mais comum. Decorre daí o caráter fortemente emocional e passional da comunicação gestual, em detrimento do racional e do inteligível. Na gestualidade representada, isso ocorre, sobretudo, quando a comunicação gestual se faz em "primeira pessoa".

A comunicação gestual entre enunciador e enunciatário ou entre narrador e narratário pode-se estabelecer em primeira ou em terceira pessoa. Há gestos "em primeira pessoa" e gestos "em terceira pessoa". Pelo olhar, pelo movimento da cabeça e das mãos, principalmente, o destinador do anúncio comunica-se direta ou indiretamente com seu destinatário. A comunicação gestual "em primeira pessoa" estabelece, além disso, o contexto temporal e espacial da situação de comunicação e produz efeitos de sentido próprios da oralidade, graças à criação desse simulacro de comunicação em situação, pois, da instituição de um eu, aqui, agora, decorrem efeitos de aproximação espacial, temporal e actorial.

Examinamos, em trabalhos anteriores, os efeitos de sentido de oralidade em textos escritos e sincréticos. Nesses estudos, analisamos os traços temporais, espaciais e actoriais que caracterizam o discurso falado e o escrito e pudemos concluir que o discurso falado produz efeitos de sentido particulares de oralidade e que esses sentidos podem ser determinados positiva ou negativamente:

\begin{tabular}{|c|c|c|}
\hline & \multicolumn{2}{|c|}{ Valorização } \\
\hline $\begin{array}{l}\text { efeitos de sentido ou } \\
\text { oralidade }\end{array}$ & positiva & negativa \\
\hline - proximidade & $\begin{array}{c}\text { subjetividade, afetividade, } \\
\text { sensorialidade }\end{array}$ & $\begin{array}{l}\text { falta de objetividade, excesso de } \\
\text { intimidade, deselegância }\end{array}$ \\
\hline - descontração, informalidade & $\begin{array}{l}\text { sinceridade, franqueza, } \\
\text { cumplicidade }\end{array}$ & excesso de envolvimento \\
\hline - falta de completude & novidade, atualidade & incompletude, má elaboração, \\
\hline - caráter passageiro & $\begin{array}{l}\text { em que tudo pode ser dito, } \\
\text { verdadeiro }\end{array}$ & $\begin{array}{l}\text { efêmero, que não dura, que tem } \\
\text { pouco efeito }\end{array}$ \\
\hline - simetria, reciprocidade & $\begin{array}{c}\text { cumplicidade, igualdade, } \\
\text { identidade }\end{array}$ & excesso de envolvimento \\
\hline
\end{tabular}


A publicidade emprega efeitos de sentido de oralidade, tentando, em geral, produzir os sentidos positivos que acabamos de mencionar. Nos anúncios, os efeitos de sentido de oralidade (de reciprocidade, de cumplicidade, de proximidade, de sinceridade) são produzidos tanto pelo verbal escrito, quanto pela gestualidade representada visualmente.

Vejamos alguns exemplos de comunicação gestual em $1^{\mathrm{a}}$ pessoa, com os efeitos de oralidade mencionados, e em $3^{\text {a }}$ pessoa, sem esses sentidos:

- comunicação gestual em $3^{\mathrm{a}}$ pessoa:
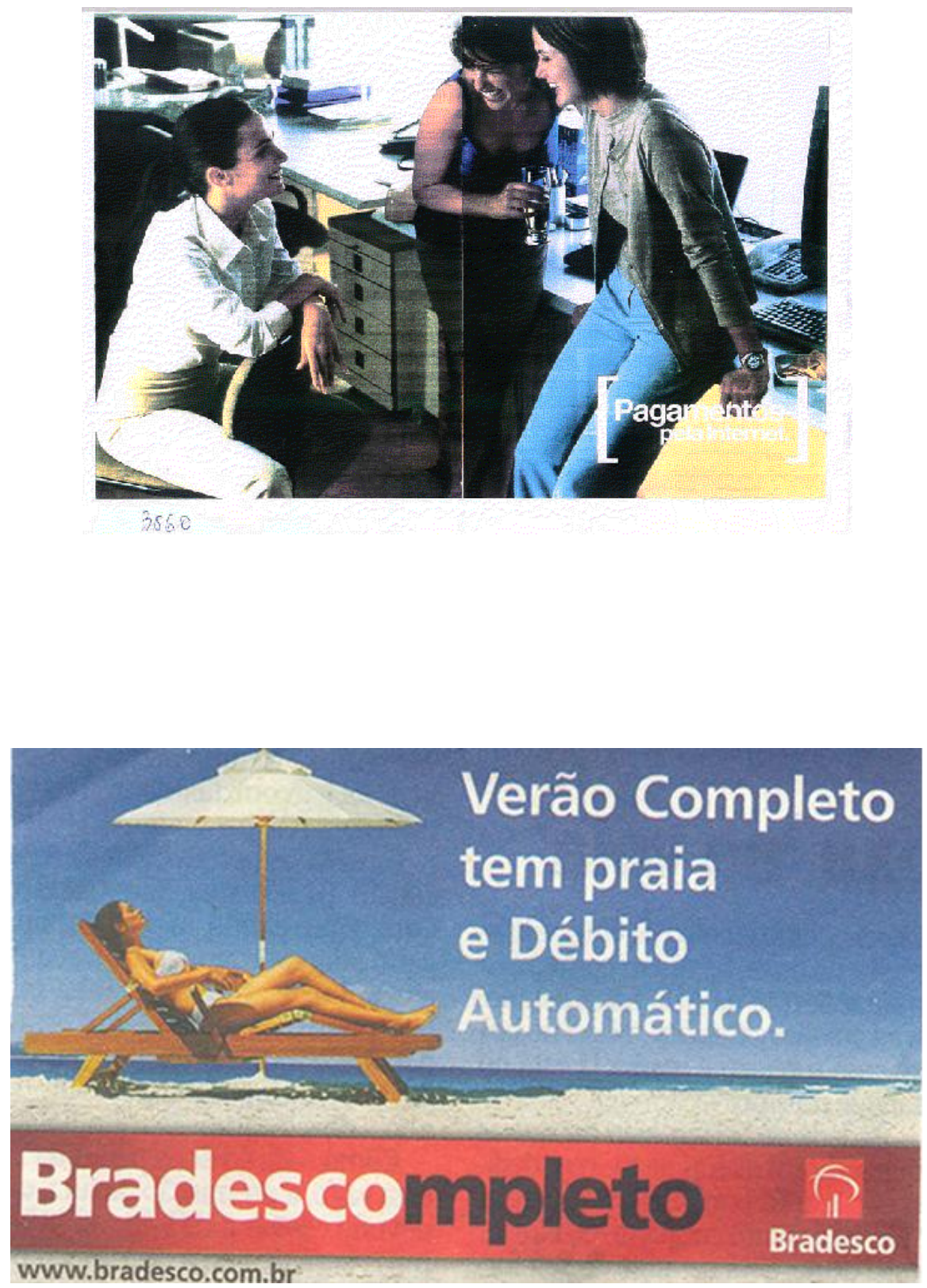
CASA, Vol.8 n.2, dezembro de 2010

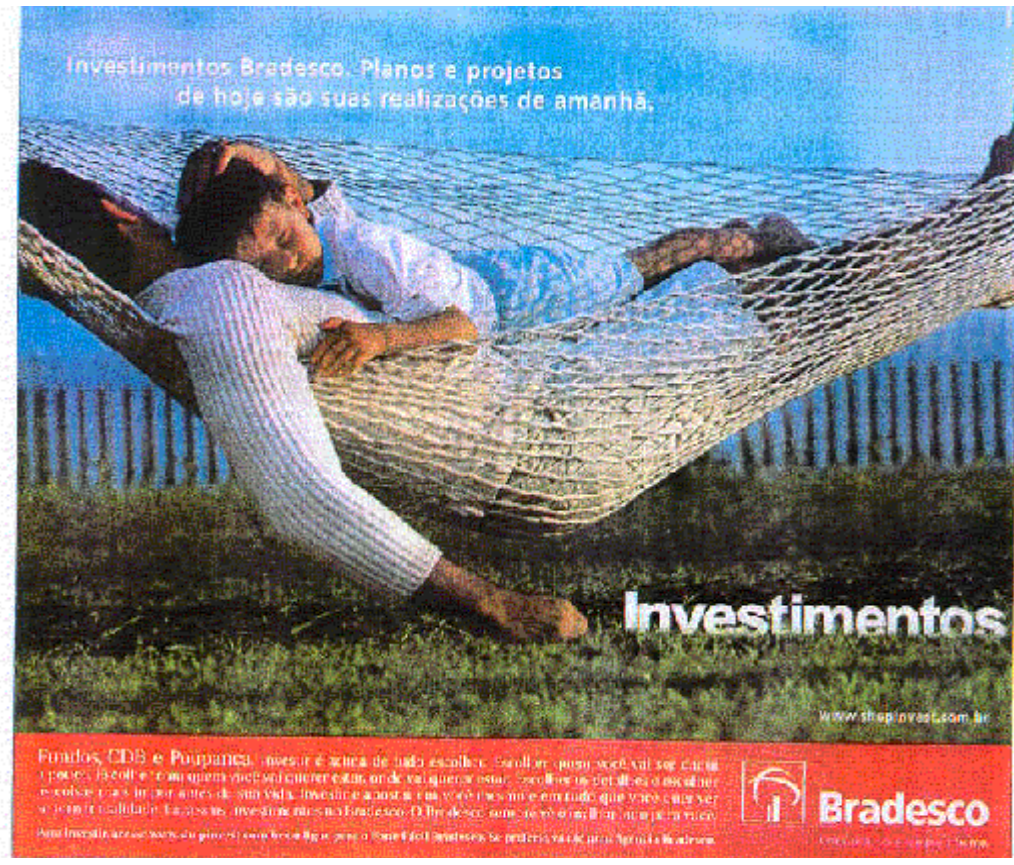

- comunicação gestual em $1^{a}$ pessoa:

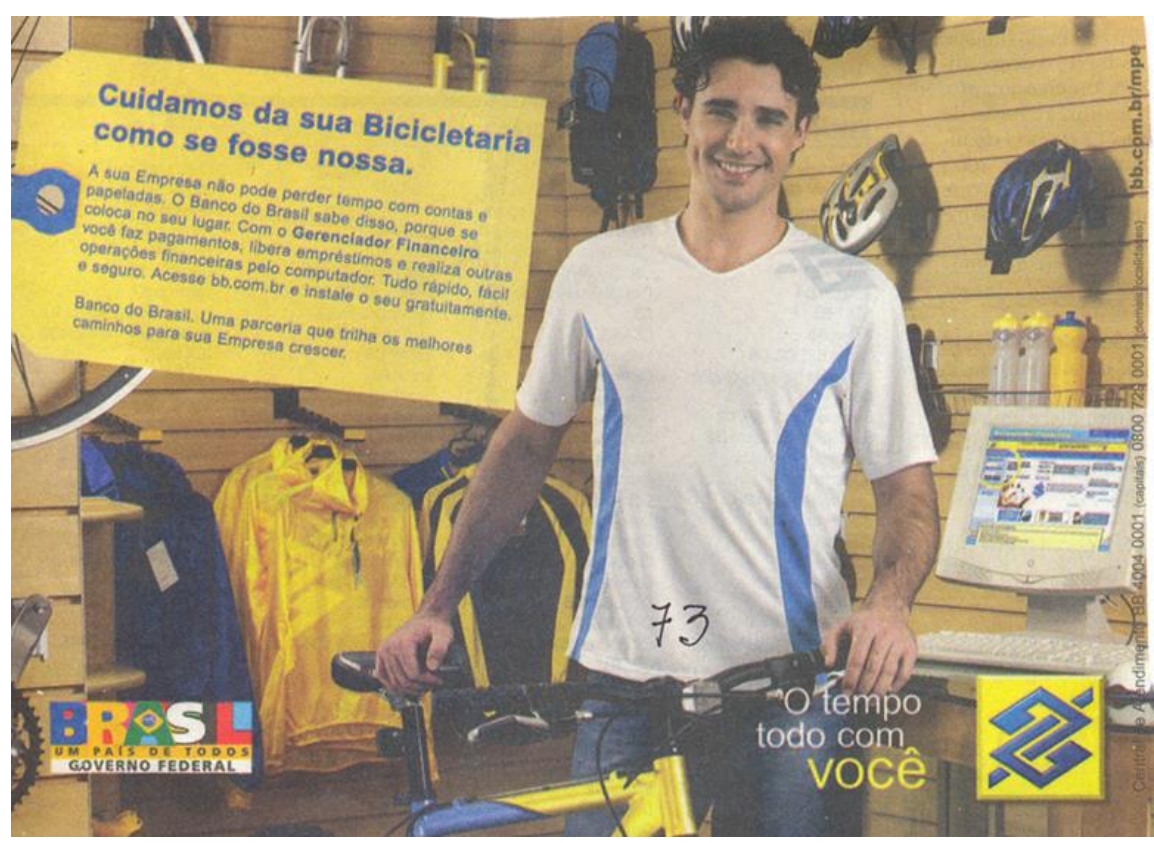

http://seer.fclar.unesp.br/casa 11 
CASA, Vol.8 n.2, dezembro de 2010
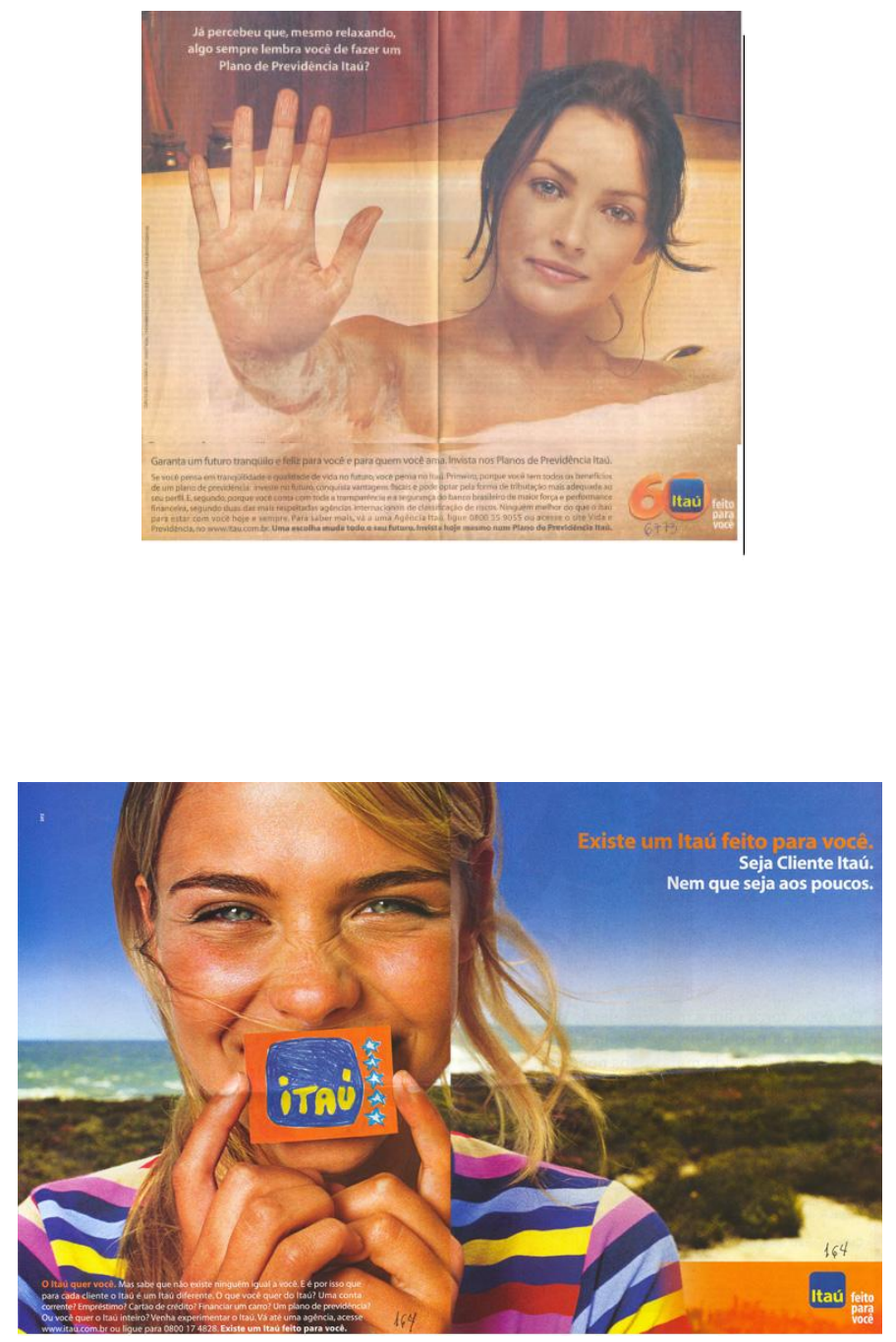

Nos textos acima, em "primeira pessoa", a gesticulação tem a função fática dominante de estabelecer a comunicação, mas também outros papéis: a função conativa ou apelativa, própria da publicidade, alguns traços da função referencial na gestualidade de "mostrar" e "indicar", e, principalmente, função emotiva. Nos anúncios com a gesticulação de "mostrar" ou "indicar", a comunicação mais informativa e racional adquire também caráter passional.

A gestualidade com função emotiva ou atributiva é muito usada nos anúncios examinados. Trata-se de gesticulação, sobretudo, do rosto, e que comunica emoções, sentimentos, paixões. Nos anúncios de bancos, são principalmente paixões de alegria, de felicidade e de prazer (por movimentos da boca e dos olhos), de tranquilidade, de serenidade e de paz (por gestos da boca, dos olhos, da mão e da postura do corpo): 

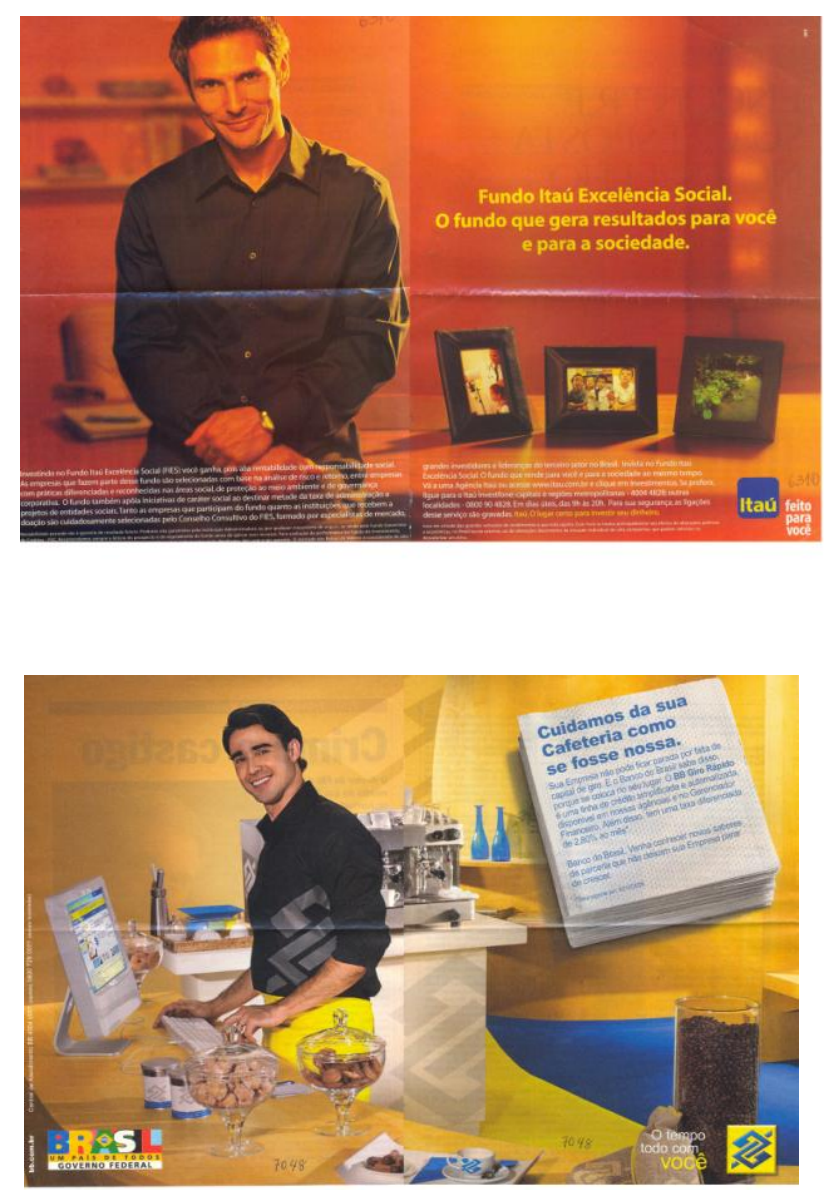

\section{Considerações finais}

A gestualidade representada no nível da enunciação dos anúncios tem, assim, papel retórico fundamental na comunicação persuasiva desses textos: assegura relações intensas entre o destinador e o destinatário, estabelece o simulacro de uma comunicação em presença, aproxima os interlocutores corporal e sensorialmente e, mesmo, quase "oralmente". Nos anúncios das instituições financeiras, os efeitos de oralidade são, sobretudo, de subjetividade, de sinceridade, de franqueza, de informalidade, de envolvimento passional entre destinador e destinatário. Essas estratégias são empregadas principalmente nos anúncios que se dirigem ao público mais jovem, às mulheres, aos aposentados, às camadas menos prestigiadas da sociedade a que o senso comum e as pesquisas de opinião atribuem sensibilidade mais aguçada aos valores emocionais e sensoriais.

Estudos semióticos da gestualidade são necessários, pois a gesticulação humana constrói o homem enquanto sujeito das ações de transformação do mundo e, sobretudo, cria a vida em sociedade, isto é, as relações corporais e passionais que ligam os homens. Duas direções de pesquisa foram propostas: o exame das transposições gestuais produtoras das gestualidades poéticas, dos tratamentos de fisioterapia e das gestualidades linguísticas (da língua de sinais); a análise da gestualidade representada e de seu papel retórico nos discursos. 
CASA, Vol.8 n.2, dezembro de 2010

\section{Referências bibliográficas}

BARROS, Diana Luz Pessoa de. A propósito do conceito de discurso urbano oral culto: definições e imagens. In: PRETI, Dino. (org.). O discurso oral culto. São Paulo: Humanitas, 1997.

Procedimentos e recursos discursivos na conversação. In: Preti, Dino. Estudos de língua falada: variações e confrontos. São Paulo, Humanitas, 1998. p. 47-69.

. Entre a fala e a escrita. Algumas reflexões sobre as posições intermediárias. In: Preti,

Dino. Fala e a escrita em questão. São Paulo, Humanitas, 2000, p.57-77.

Interação em anúncios publicitários. In: Preti, Dino. Interação na fala e na escrita.

São Paulo, Humanitas, 2002, p.17-44.

Efeitos de oralidade no texto escrito. In: Preti, Dino. Oralidade em diferentes discursos. São Paulo: Humanitas, 2006, p. 57-84.

FIORIN, José Luiz. Linguagem e ideologia. São Paulo, Ática, 1988.

FLOCH, Jean-Marie. Petites mythologies de l'oeil et de l'esprit. Paris: Amsterdam, HadèsBenjamins, 1985.

FONTANILLE, Jacques e ZILBERBERG, Claude. Tensão e significação. São Paulo: Discurso/Humanitas, 1988 (original francês); 2001.

GREIMAS, Algirdas Julien. Du sens. Paris : Éditions du Seuil, 1970.

.De l'imperfection. Paris : Pierre Fanlac, 1987.

GREIMAS, A-J et COURTÉS, J. Sémiotique. Dictionnaire raisonné de la théorie de langage. Paris : Hachette, 1979.

GREIMAS, A. J. e FONTANILLE, J. Semiótica das paixões. São Paulo: Ática, 1993.

TROTTA, Mariana de Rosa. O discurso da dança: uma perspectiva semiótica. São Paulo, Universidade de São Paulo, Dissertação de mestrado, 2004, 139 p. 